\section{Is There Calm After the Storm? A General Practice Registry-based Study Following the Case of a Severe Hailstorm in the Netherlands}

Dr. Christos Baliatsas, Dr. Joris Yzermans, Dr. Mark Nielen, Dr. Michel Dückers

Netherlands institute for health services research (NIVEL),

Utrecht, Netherlands

Introduction: On June 23 and 24, 2016, a heavy hailstorm in the south of the Netherlands destroyed farms, greenhouses, and crops, and caused severe damage to many residences and cars in multiple communities. The size of the massive hailstones ranged from 3 to 5 centimeters in diameter. The farm damages alone were estimated to be 100 million euros, while total insurance industry losses were expected to exceed half a billion euros. In addition to the storm, the affected region also had its first tropical day of the year, with temperatures reaching 32 degrees Celsius. To date, the psychosocial impact and possible adverse health effects caused by the storm have not been thoroughly investigated.

Aim: To explore whether the occurrence of chronic and acute health problems in the affected region increased after the hailstorm compared to "control" areas.
Methods: Health data for the time period before (2013-2015) and immediately after the hailstorm (2016-2018) will be collected based on electronic health records (morbidity, psychosocial problems, and prescribed medication) from general practices (GP) located in the affected municipalities. For the same period, health problems in the affected region will also be compared with GP-registered data from different Dutch municipalities with similar urbanization levels, which will be used as a control group. The combination with external datasets (e.g. socioeconomic status, environmental exposures) will also be considered.

Results: Multilevel regression analyses will be carried out to test the health impact of this sudden, onset event. The current study is a work in progress. Final results are expected in February 2019 and are presented during the conference.

Discussion: The present study illustrates how routinely collected patient health records, recorded by GPs, can be used for epidemiological research in the aftermath of a disaster within the context of climate and weather extremes in Europe.

Prehosp. Disaster Med. 2019;34(Suppl. 1):s49

doi:10.1017/S1049023X19001158 